\title{
How should I treat an Edwards SAPIEN 3 aortic valve embolisation during a transaortic transcatheter aortic valve implantation
}

Fournier, Stephane ; Monney, Pierre ; Roguelov, Christian ; Ferrari, Enrico ; Eeckhout, Eric ; Muller, Olivier ; Durko, Andras ; Van Mieghem, Nicolas M ; Kappetein, Arie Pieter ; Margey, Ronan

DOI: https://doi.org/10.4244/EIJ-D-16-00592

Posted at the Zurich Open Repository and Archive, University of Zurich ZORA URL: https://doi.org/10.5167/uzh-146768

Journal Article

Published Version

Originally published at:

Fournier, Stephane; Monney, Pierre; Roguelov, Christian; Ferrari, Enrico; Eeckhout, Eric; Muller, Olivier; Durko, Andras; Van Mieghem, Nicolas M; Kappetein, Arie Pieter; Margey, Ronan (2017). How should I treat an Edwards SAPIEN 3 aortic valve embolisation during a transaortic transcatheter aortic valve implantation. EuroIntervention, 13(4):495-498.

DOI: https://doi.org/10.4244/EIJ-D-16-00592 


\section{How should I treat an Edwards SAPIEN 3 aortic valve embolisation during a transaortic transcatheter aortic valve implantation?}

Published on 20 July 2017

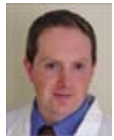

Stephane Fournier ${ }^{1}, \mathrm{MD}$; Pierre Monney ${ }^{1}, \mathrm{MD}$; Christian Roguelov ${ }^{1}$ MD; Enrico Ferrari ${ }^{2}, \mathrm{MD}$; Eric Eeckhout ${ }^{1}, \mathrm{MD}, \mathrm{PhD}$; Olivier Muller ${ }^{1 *}$, MD, PhD, Andras Durko ${ }^{3}$, MD; Nicolas M. Van Mieghem ${ }^{4}, \mathrm{MD}, \mathrm{PhD}$; Arie Pieter Kappetein ${ }^{3}, \mathrm{MD}$, PhD; Ronan Margey ${ }^{5}, \mathrm{MB}, \mathrm{BAO}, \mathrm{BCh}$, MRCPI, FACC, FESC

1. Department of Cardiology, University Hospital Center Vaudois (CHUV), Lausanne, Switzerland; 2. Department of Cardiac Surgery, Cardiocentro Ticino Foundation, Lugano, Switzerland; 3. Department of Thoracic Surgery, Thoraxcenter, Erasmus MC, Rotterdam, the Netherlands; 4. Department of Interventional Cardiology, Thoraxcenter, Erasmus MC, Rotterdam, the Netherlands; 5. Department of Cardiology, Mater Private Hospital Cork, Cork, Ireland

The authors have no conflicts of interest to declare.

\section{How would I treat?}

\section{THE INVITED EXPERT'S OPINION}

Ronan Margey ${ }^{5 *}$, MB, BAO, BCh, MRCPI, FACC, FESC

5. Department of Cardiology, Mater Private Hospital Cork, Cork, Ireland

${ }^{*}$ Corresponding author: Department of Cardiology, Mater Private Hospital Cork, City Gate, Cork, Ireland. E-mail: ronan.margey@materprivate.ie

Transcatheter aortic valve embolisation is a rare but often catastrophic complication of transcatheter aortic valve implantation (TAVI). The incidence of embolisation of the SAPIEN valve has declined over time with improved operator experience, use of CT aortic annular measurements to guide sizing, accurate identification of co-planar valve deployment angles, accurate valve prosthesis positioning, and the availability of larger-sized prostheses. However, embolisation still occurs with an incidence of $0.5-0.8 \%$. Most embolisation, as in this case, occurs into the ascending aorta or supra-annular location, but embolisation into the left ventricular outflow tract and left ventricular cavity can also occur. In the published literature, aortic embolisation is managed by placing a second TAVI device and deploying the embolised valve in an aortic location. The embolised valve leaflets remain fully open, essentially functioning as a "covered stent".

As with any procedural complications, prevention is often better than trying to solve the problem post hoc, so in this case I would start by suggesting that, when there was extreme difficulty in advancing the delivery system into the sheath resulting in movement of the stent-valve frame on the delivery balloon, I would have removed the system and re-prepared the entire delivery system or mounted a new valve and delivery system.

\section{AUTHORS}

- Fournier S

- Monney P

- Roguelov C

- Ferrari E

- Eeckhout E

- Muller O

- Durko A

- Van Mieghem N

- Kappetein A

- Margey R 
re-inflate the embolised valve frame fully. I would then remove the existing delivery system, re-insert the sheath introducer/dilator and re-advance the sheath with its introducer through the embolised valve frame to facilitate unobstructed advancement of a second valve mounted on a new delivery system.

I would then go ahead and perform a standard TAVI implant under rapid RV pacing control with a new $26 \mathrm{~mm}$ SAPIEN 3 transcatheter valve delivery system.

Based on the fact that this patient has significant atherothrombotic material in the aortic arch, I would suggest leaving the embolised valve in the ascending aorta and not trying to snare the device and pull it across the aortic arch. I would withdraw the sheath until the embolised valve was fully uncovered. Using preprocedural CT dimensions, I would take an oversized balloon approximating the ascending aortic dimensions and post-dilate the embolised valve frame into position in the ascending aorta.

An alternative strategy would be to deploy a second $26 \mathrm{~mm}$ SAPIEN 3 valve in the correct location and then place the patient on femoro-femoral arteriovenous circulatory bypass and open the ascending aorta to remove the embolised valve directly. However, given the patient's atherosclerotic aortic disease, I feel this would carry a substantial risk of stroke and perioperative morbidity.

- OR

SIGN IN

to access the full

article.

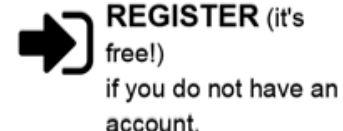

account. 